\title{
SPORTS CONSUMPTION BEHAVIOR: DISCOVERING TYPOLOGIES OF AMATEUR CYCLISTS
}

\author{
LUCA FERRUCCI, FABIO FORLANI, ANTONIO PICCIOTTI
}

\author{
University of Perugia, Department of Economics
}

Mailing address: Fabio Forlani, University of Perugia, Department of Economics, 20 Via Pascoli, 06123 Perugia, tel.: +393282162130, e-mail: fabio.forlani@unipg.it

\begin{abstract}
Introduction. Cycling is one of the most popular and practiced sports both in Europe and globally. However, management studies aimed at defining cyclists' consumption behavior are still limited. The most recent contributions describe cycling consumption as an activity heavily influenced by the intensity and sociality of its practice but do not highlight the importance of expenditures related to participation in amateur cycling events and cycle tourism experiences. Starting from these behavioral dimensions, the article proposes an original segmentation of the sport and leisure market, leading to the identification of different profiles of amateur cyclists. Material and methods. The research was conducted on a sample of 182 cyclists located in one single Italian region to ensure a high level of social, economic and cultural uniformity. The data was collected by conducting a questionnaire, and its resulting information relating to sport and consumer behavior was processed through a cluster analysis procedure. Results. The results reveal the existence of five different amateur cyclists' profiles (the parsimonious, the competitive, the ostentatious, the sociable and the experiential), each distinguished by specific behavior in terms of the intensity and way of conducting the sports activity and the propensity to incur different types of expenditure. Conclusions. From a theoretical point of view, the results confirm the effectiveness of behavioral segmentation in the market of sports consumption. From an operational point of view, they provide useful marketing indications for businesses operating in the sport-system chain and destination management operators.
\end{abstract}

Key words: cycling, cycling tourism, cycling experience, sport expenditures, sport behavioural segmentation

\section{Introduction}

Cycling is one of the most practiced sports in the world. It ranks in the top ten in Europe and the top five in Italy, France and Spain. Amateur cycling, which is practiced for fun, health and tourism reasons, is one of the most popular sports in Europe $[1,2]$. In Italy, according to the Italian National Institute of Statistics data [3], 11.9\% of individuals who practice sports carry out a cycling activity (about 2,414,000 people). Cycling generates both a significant volume of direct consumption, as demonstrated by the 2,010,000 bicycles sold in 2020 [4], and an important growth in allied tourist and recreational activities (21.9 million of cycle tourists, corresponding to $2.4 \%$ of the Italian tourist movement in 2018) [5].

Despite this data which demonstrates the existence of a quickly growing phenomenon, research on cycling, in management perspective, is still limited. Some studies investigate the spending behavior of sportspeople, considering it relevant to the marketing implications that may arise for businesses [1]. Other studies analyze these behaviors by focusing on the impact of sport tourism on tourist destinations $[6,7,8,9]$.

With regards to the first issue (the spending behavior of sportspeople for marketing purposes), the theoretical framework most commonly used is the traditionally neoclassical one, which bases its theories on the axioms typical of this paradigm: consumer rationality; utility maximization (given the constraints of time and money); stability of preferences and market balance $[1,10,11]$. The reference is Becker's "theory of household production" [12], according to which economic decisions of individuals are fundamentally determined by their available income and the amount of time dedicated to sports [13].

Other authors have, however, highlighted how consumers' behavior in sport does not appear to be completely rational (they do not possess nor process some information) and is influenced by psychological and social factors $[2,10,14]$. As argued by Ohl and Tasks [15], for example, people purchase sports goods in or- der to belong to a certain group, or quite the opposite, to build their own identity and to distinguish themselves from others.

In more recent literature, these two perspectives tend to converge. While keeping the basis of Becker's theory (time and money available to the consumer), sport management researchers recognize the importance of other factors that influence consumer behavior of sportspeople [1, 13, 16, 17, 18]. It is within this strand of research that the only work related to the spending behavior of amateur cyclists [1] can be found. In this latter article, the authors envisage several categories of determinants which can influence spending behavior. In addition to socio-demographic variables (sex, age, children, partner, education, profession), the following are also considered: cycling intensity variables (duration, frequency, level of performance, context, number of cycling variants) related to "the level at which cycling is practiced", socio-economic cycling capital variables (cycling on TV, training program, literature, website, cycling years, other sports) related to "the knowledge about cycling goods and services", AIOs, namely Attitudes, Interests, Opinions (health, real sport, cycling identification, cycling drop out and low thresholds) which incorporate "people's feelings and thoughts about cycling participation and cycling consumption". The results of the research confirm the importance of sport-specific determinants: "Cycling expenditure is more influenced by sports intensity variables and AIOs than by classic orthodox socio-economic and socio-demographic variables. Apparently, sports expenses not only stem from rational decisions as suggested by the orthodox economic approach, but are also influenced by how sports participants feel and think about sports participation" [1]. As the authors themselves claim, the work carried out is a prerequisite for implementing effective market segmentation and for providing useful guidance, in terms of marketing, to both sports governing bodies and businesses: "this opens up opportunities for market segmentation, which is a key element in effective marketing planning" [1].

With regards to the second topic (effects deriving from sport tourism), the tourist behavior of cyclists is analyzed, with 
a focus on the individual disciplines practiced [7], the features of cycling events $[19,20]$ and the impact that cycling tourism can have on tourist destinations [8, 9, 21, 22, 23, 24].

There is currently no available work that analyzes and links the expenditure of cyclists in their sports practice with that of their tourist one [6]. As proof of this, in sport management literature, the expenditures incurred for the practice of sport are generally classified according to two different approaches: the first one considers exclusively the expenditures directly related to the sports activity $[13,18]$, the second one also includes the indirect expenditures [14, 16]. However, neither of these two viewpoints separates household sport expenditures from the expenses incurred to take part in sports events and tourism experiences.

With reference to cycling, Thibaut et al. [1] divide expenditures into non-durable and durable goods. Nine different products (goods and services) which are normally purchased once or more times per year belong to the first category (non-durable - frequent purchases): Bike rental and/or bike material; Bicycle repair; Clothes/sportswear (sports glasses included); Sports drink and Food; Information about cycling; Membership fee of a cycling club; Membership of a fitness center; Cycling events and bike races; Other frequent expenses. The second category (durable goods) includes: Bike purchase, Home trainer purchase; Helmet; Cycling shoes; Cycling material; Heart rate monitor; Other durable goods.

Within this context, two possible theoretical gaps may be outlined:

- on the one hand, there is a lack of attempts to segment the consumption patterns of amateur cyclists on a behavioral basis (intensity of practice, sociality of practice and expenditure incurred). The studies conducted so far [1] highlight the factors that most influence spending behavior but do not offer unambiguous and well-delineated profiles;

- on the other hand, there is a lack of studies analyzing both sports and tourism consumption [6]. Available research tends to keep these two different dimensions separate, with tourism expenditure not falling under the category of sports expenditure.

The aim of this work is, therefore, to define the main types of amateur cyclist consumption behavior and conceive typical profiles, taking into account, in a combined manner, dimensions relating both to the practice of sport and to the overall expenditures incurred (durables, consumption, events, experiences).

\section{Material and Methods}

The objective of this research is of explorative nature: to verify the feasibility and use of behavioral segmentation in sports expenditure. However, the decision to practice cycling can be influenced by many factors such as, for example, the cycling tradition, the availability of infrastructures or the spread of cycling associations. These factors show a different level of presence on the Italian territory [5]. For this reason, in order to avoid the comparison of cyclists belonging to different social and cultural contexts and to limit the influence of similar aspects, it was decided to study a sample of amateur cyclists coming from the same Italy region, Umbria. The choice of the single location ensured that the subjects' behavior would not be influenced by variables dependent on different social or cultural backgrounds. Umbria was chosen for its limited dimension (900,000 residents in 2021), for its geographical position in the center of Italy and for the number of its cycling enthusiasts and cycling clubs above the national average. In fact, based on the data of the Italian Cycling Federation, in 2021 Umbria holds 2.42\% of Italian cycling clubs and $2.41 \%$ of cycling members, despite having an overall population of just $1.46 \%$ of the Italian one.

The data collection was conducted by means of a structured survey administered to a random sample of amateur cyclists who were reached through cycling clubs or specialized shops located throughout Umbria. At the end of the survey, complete information was collected on a sample of 182 amateur cyclists. The sample obtained was made up of people whose socio-demographic characteristics (sex, age, educational qualification, profession, family status) conformed to the typical characteristics of the Italian amateur cyclist.

The survey used was prepared on the basis of the evidence emerging from the scientific literature and was divided into several sections, aimed at collecting information of a socio-demographic and behavioral nature. The variables identified refer to: - the intensity of sports practice [1]. The proxy variables representing this dimension are the average annual kilometers covered (AAK, Annual Average Km), calculated as the average value of the ones recorded in 2019 and 2020, and the number of weekly outings (WW, Weekly Workout). The hypothesis behind this choice is as follows: the greater the intensity of practice, i.e. the number of times cycling is practiced and the total distances covered on average each year, the greater the involvement and passion for the sport;

- years and socialization of sports practice [18]. The proxy variable used is membership or non-membership and the period of membership, in terms of years, to sports clubs (SCL, Sports Club). The underlying hypothesis is as follows: membership of a club for an increasing number of years indicates both the endurance of sports passion and the tendency to socialize this practice;

- the number of bicycles owned. The hypothesis is that the number of bicycles owned (NBIK, Number of Bikes) and thus the tendency to accumulate rather than replace them, indicates the intensity of the affective and emotional connection with cycling;

- expenses incurred for sporting activities. In relation to the latter dimension, a taxonomy of sports expenditure is proposed that merges the one traditionally found in literature [1] with dimensions of experiential tourism consumption [19, 25]. In particular, the following are considered:

o the total expenditures incurred in the last 5 years for bicycles purchased (BIKEX, Bikes Expenses);

o expenditure incurred annually for the purchase of durable goods and services other than bicycles, such as technical clothing, computers, helmets, shoes, etc., (INVEX, Investment Expenses);

o expenditure, again annual, for the purchase of non-durable goods and services of a recurrent nature, such as the periodic maintenance of a bicycle or the purchase of food supplements (CONSEX, Consumer Expenses);

o annual expenses incurred for participation in events, such as registration and participation in local, national or international amateur competitions (EVEX, Event Expenses);

o annual expenditure on tourism experiences or holidays based almost exclusively on cycling (TEXEX, Tourism Experiences Expenses).

The hypothesis of this work is that by considering these behavioral variables, it is possible to segment the amateur cyclist market in an effective and meaningful manner. To carry out this operation, the classic methodology of cluster analysis was used. Given the quantitative and heterogeneous nature of the variables, they were first standardized and then assembled. The method used was the K-Means. After a series of tests, five clus- 
ters were identified, capable of ensuring a balance between the variety of behaviors detected and the numerical significance/ consistency of the groups.

The clusters obtained were then analyzed using variables of a socio-demographic nature which, as simple descriptors and on the basis of an a posteriori segmentation logic [26], made it possible to provide an overall picture of the characteristics of amateur cyclists belonging to the individual clusters.

Table 1. The cluster centroids

\begin{tabular}{|c|c|c|c|c|c|c|c|c|c|c|c|}
\hline Cluster & AAK & WW & SCL & NBIK & BIKEX & INVEX & CONSEX & EVEX & $\begin{array}{c}\text { TEXEX } \\
\begin{array}{c}\text { Sum of } \\
\text { weights }\end{array}\end{array}$ & $\begin{array}{c}\text { Within-class } \\
\text { variance }\end{array}$ \\
\hline 1 & -0.729 & -0.798 & -0.549 & -0.289 & -0.455 & -0.392 & -0.263 & -0.485 & -0.263 & 67.000 & 2.892 \\
\hline 2 & 0.600 & 0.668 & -0.232 & -0.379 & -0.065 & -0.034 & 0.082 & 0.081 & -0.258 & 61.000 & 4.647 \\
\hline 3 & 0.225 & 0.418 & 0.148 & 0.886 & 1.278 & 1.701 & 1.227 & 0.187 & -0.209 & 22.000 & 11.350 \\
\hline 4 & 0.289 & 0.114 & 2.016 & 1.088 & 0.185 & -0.506 & -0.624 & -0.207 & 0.200 & 20.000 & 7.528 \\
\hline 5 & 0.130 & 0.100 & 0.612 & 0.102 & 0.217 & 0.085 & -0.162 & 2.302 & 2.829 & 12.000 & 11.135 \\
\hline
\end{tabular}

Table 2. Distances between the class centroids

\begin{tabular}{|c|c|c|c|c|c|}
\hline & 1 & 2 & 3 & 4 & 5 \\
\hline 1 & 0 & & & & \\
\hline 2 & 2.178 & 0 & & & \\
\hline 3 & 3.783 & 2.843 & 0 & & \\
\hline 4 & 3.345 & 2.947 & 3.666 & 0 & \\
\hline 5 & 4.589 & 4.013 & 4.507 & 4.091 & 0 \\
\hline
\end{tabular}

Table 3. Socio-demographic description of clusters

\begin{tabular}{|c|c|c|c|c|c|}
\hline Variables & $\begin{array}{l}\text { Clus- } \\
\text { ter } 1\end{array}$ & $\begin{array}{l}\text { Clus- } \\
\text { ter } 2\end{array}$ & $\begin{array}{l}\text { Clus- } \\
\text { ter } 3\end{array}$ & $\begin{array}{l}\text { Clus- } \\
\text { ter } 4\end{array}$ & $\begin{array}{l}\text { Clus- } \\
\text { ter } 5\end{array}$ \\
\hline \multicolumn{6}{|l|}{ Gender } \\
\hline M & 82.1 & 93.4 & 90.9 & 95.0 & 83.3 \\
\hline $\mathrm{F}$ & 17.9 & 6.6 & 9.1 & 5.0 & 16.7 \\
\hline \multicolumn{6}{|l|}{ Age } \\
\hline $18-30$ & 10.4 & 13.1 & & 5.0 & \\
\hline $31-45$ & 34.3 & 34.4 & 31.8 & & 8.3 \\
\hline $46-65$ & 53.7 & 52.5 & 63.6 & 60.0 & 75.0 \\
\hline Over 65 & 1.5 & & 4.5 & 35.0 & 16.7 \\
\hline \multicolumn{6}{|l|}{ Education } \\
\hline Middle School & 13.4 & 21.3 & 9.1 & 5.0 & 8.3 \\
\hline Diploma & 59.7 & 47.5 & 54.5 & 65.0 & 75.0 \\
\hline Degree & 22.4 & 27.9 & 31.8 & 30.0 & 16.7 \\
\hline Post-lauream & 4.5 & 3.3 & 4.5 & & \\
\hline \multicolumn{6}{|l|}{ Profession } \\
\hline Employee & 64.2 & 50.8 & 45.5 & 10.0 & 33.3 \\
\hline Director & 9.0 & 3.3 & 13.6 & 5.0 & 8.3 \\
\hline Professional/self-employed & 23.9 & 27.9 & 31.8 & 30.0 & 33.3 \\
\hline Retired & 3.0 & 9.8 & 9.1 & 50.0 & 25.0 \\
\hline Unemployed/student & & 8.2 & & 5.0 & \\
\hline \multicolumn{6}{|l|}{ Family condition } \\
\hline No children & 41.8 & 42.6 & 31.8 & 5.0 & 33.3 \\
\hline Children under 14 years old & 28.4 & 23.0 & 31.8 & 5.0 & 8.3 \\
\hline Children over 14 years old & 29.9 & 34.4 & 36.4 & 90.0 & 58.3 \\
\hline
\end{tabular}

\section{Results}

The clusters identified display specific characteristics that are reported in the tables below. After defining the distinctive behavioral characteristics of the individual clusters (Tab. 1), measuring the distances between their centroids (Tab. 2) and providing a socio-demographic description (Tab. 3), different types of amateur cyclists (Tab. 4) are defined.

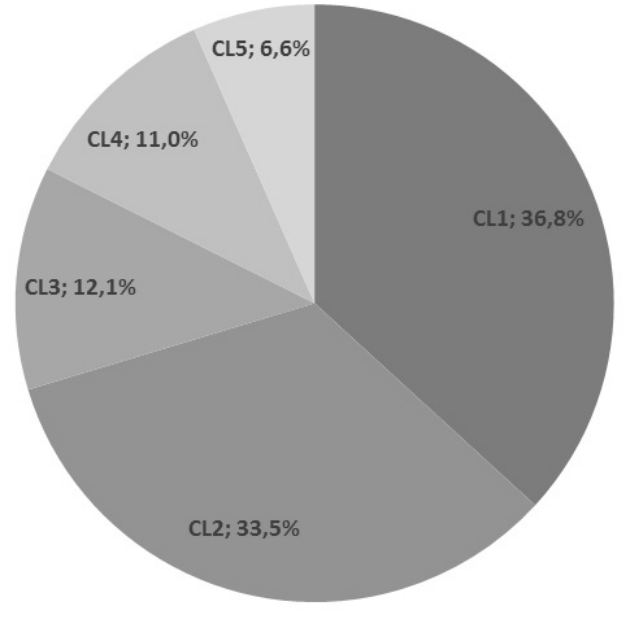

Figure 1. Cluster distribution

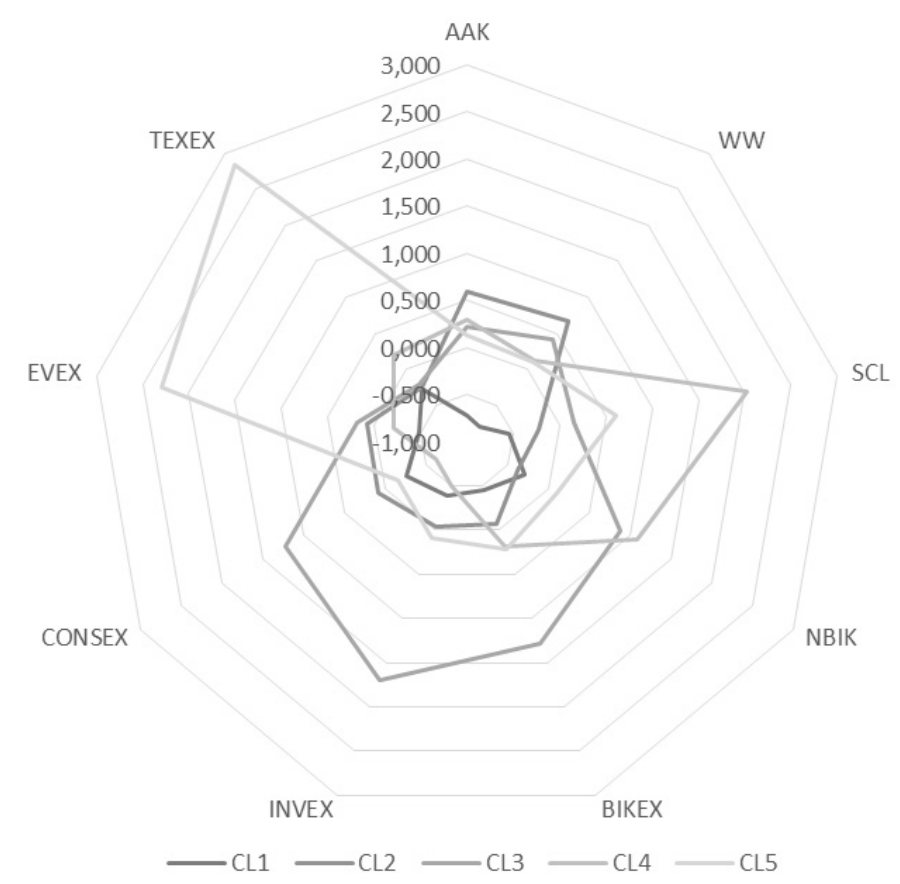

Figure 2. Cluster specificity 
Table 4. Clusters identification

\begin{tabular}{|c|c|}
\hline $\begin{array}{c}\text { Cluster } \\
\text { definition }\end{array}$ & Cluster description \\
\hline $\begin{array}{l}\text { The parsimonious } \\
\text { (Cluster } 1 \text { ) }\end{array}$ & $\begin{array}{l}\text { Cyclists belonging to this cluster are very numerous (37\%) but show a low intensity of practice, low social involvement and minimal expendi- } \\
\text { ture in all the considered types. These subjects have the lowest values in terms of intensity of practice, participation in amateur club activities } \\
\text { and spending on bicycles, events and tourist experiences. The other levels of expenditure (on investment and consumption) are also, if not } \\
\text { the worst compared to other types of cyclists, certainly among the lowest. Analyzing the socio-demographic variables, this cluster is the one } \\
\text { with the greatest presence of young people and women, often childless, with an intermediate level of education and not particularly qualified } \\
\text { employment. From an interpretative aspect, two profiles of amateur cyclists can be hypothesized: a) the beginner or novice cyclist who is at } \\
\text { an early stage in the sport and who does not intend to spend large sums of money; b) the detached cyclist who decides to practice this sport } \\
\text { not for passion or to share experiences with others but for different reasons, such as health reasons. }\end{array}$ \\
\hline $\begin{array}{l}\text { The competitive } \\
\text { (Cluster 2) }\end{array}$ & $\begin{array}{l}\text { A large number of cyclists belong to this cluster (34\%). They make the highest number of weekly trips and cover the highest average number } \\
\text { of kilometers per year, thus showing the highest level of intensity. This amateur cyclist does not own many bicycles and has a lower than av- } \\
\text { erage level of membership in sports associations. In terms of spending behavior, he/she spends more on consumption, shows intermediate } \\
\text { levels of spending on investment and participation in events and does not consider cycling as an opportunity for tourist experiences. From } \\
\text { a socio-demographic point of view, this cluster has similar characteristics to the previous one. In fact, there is a greater presence of young } \\
\text { people ( } 18-30 \text { years) and adults ( } 31-45 \text { years). The level of education is not particularly high ( } 21.3 \% \text { have a secondary school certificate), as } \\
\text { well as the type of occupation (more than } 50 \% \text { are workers/employees) and also the family commitment appears low ( } 42.6 \% \text { are childless). } \\
\text { From an interpretative point of view, it is plausible to hypothesize that the lower career expectations, the availability of free time and an } \\
\text { adequate income to allocate to passions represent the prerequisites for this cyclist to practice sport with greater intensity than others. He/ } \\
\text { she is therefore a cyclist who tends to do a lot of sport, striving for high performance and likes to show it off by taking part in competitive } \\
\text { events (gran fondo, etc.) near and far from home. }\end{array}$ \\
\hline $\begin{array}{l}\text { The ostentatious } \\
\text { (Cluster 3) }\end{array}$ & $\begin{array}{l}\text { There are not many cyclists belonging to this cluster (13\%) but they are the highest spenders. This cyclist spends a lot of money on sporting } \\
\text { activities, although his/her intensity is average. He/she is an enthusiast who owns many bicycles (tendency to accumulate), spends contin- } \\
\text { uously on the purchase of new bicycles, on technical improvements (durable investments) and on consumption. Like the cyclist in cluster } \\
2 \text {, he/she likes to participate in events, but is more interested in cycling tourist experiences. From a socio-demographic point of view, this } \\
\text { cluster is made up of mature people ( } 45-65 \text { years old), with a medium-high level of education (it is the cluster with the highest percentage of } \\
\text { university graduates, } 31.8 \%) \text {, both employed (manual worker/employee) and self-employed (professional/entrepreneur) and with relatively } \\
\text { grown-up children. They are therefore cyclists with a high spending capacity but not a lot of time available to devote to the sporting activity. } \\
\text { They probably manage to get out on their bikes during work breaks (e.g. during their lunch break), but they do not give up their passion, } \\
\text { which they also demonstrate by showing off the best equipment and participating in cycling events. }\end{array}$ \\
\hline $\begin{array}{c}\text { The sociable } \\
\text { (Cluster 4) }\end{array}$ & $\begin{array}{l}\text { The cyclist belonging to this cluster spends much more on bicycles than on the consumption costs of the sporting activity and has a lot of free } \\
\text { time that they dedicate to the club and their sporting passion. They make up } 11 \% \text { of the cyclist sample, they show the longest membership } \\
\text { in amateur teams and own the highest number of bicycles, probably due to their long practice of the sport (historical bicycles accumulator). } \\
\text { This type of cyclist covers an average of several kilometers per year and goes out several times a week. However, they tend to spend little } \\
\text { on investment and consumption. Expenditure on events participation is also low, while these cyclists often associate their passion for this } \\
\text { sport with tourist experiences. The socio-demographic profile confirms the above. It is, in fact, a cluster of older people ( } 35 \% \text { are over } 65 \\
\text { years old), often retired ( } 50 \%) \text {, with medium-high levels of education and with adult children who have left the household. To sum up, this is } \\
\text { a cyclist who has a good economic condition that allows him/her to make significant expenditures on cycling but probably, as he/she gets } \\
\text { older, he/she tends to decrease the typical consumption generated by the pursuit of sporting performance. The large amount of free time } \\
\text { available allows him/her to devote himself/herself to sport and the activities of his/her club. }\end{array}$ \\
\hline $\begin{array}{l}\text { The experiential } \\
\text { (Cluster } 5)\end{array}$ & $\begin{array}{l}\text { The cyclists belonging to this cluster are the least significant in terms of numbers }(7 \%) \text { but are extremely interesting in terms of consumption } \\
\text { patterns. They are characterized by the fact that they spend more than the average, have time and income to devote to sport and use them } \\
\text { mainly to participate in events and to enjoy tourist experiences associated with cycling. Although these people do not have a large number } \\
\text { of bicycles, they tend to spend significantly on their purchase and investment costs. They do not go out weekly very often and do not cover } \\
\text { many kilometers annually, but they are very keen to join and participate in activities organized by amateur teams. They are mature people } \\
\text { (46-65 years old), with an intermediate level of education (diploma) and with different occupations. Again, their personal situation, i.e. the } \\
\text { absence of children in the household, allows them to have time available to devote to this sport. They are therefore the bicycle-tourist par } \\
\text { excellence, who find in the bicycle the opportunity to experience new things, often as a couple (the second largest cluster for women) or in } \\
\text { the company of cyclist friends. }\end{array}$ \\
\hline
\end{tabular}

\section{Discussion}

The first aspect that can be observed is that the cluster analysis reveals five very different profiles of cyclists, both in terms of intensity and sociality of cycling, and in terms of the type of consumption and amount of sports expenditure. However, there are aspects that all cyclists have in common and these characteristics are essentially related to their socio-demographic profile. The amateur cyclist that emerges from the research is, in fact, an adult (from 45 to 65 years old), largely male and with a medium-high level of education. Taking into account that the sample analyzed is made up of amateur cyclists with similar geo-cultural characteristics (subjects carrying out their activity in a ho- mogeneous cultural area), the study, from a strictly theoretical point of view, makes it possible to: a) confirm the importance of behavioral variables, as indicated in the literature [1]; b) test the effectiveness of behavioral segmentation as a methodology that allows for the identification of demand segments with specific needs and expectations that, in turn, determine significantly different purchase attitudes and sports consumption; c) to test the importance of including experiential-type consumption [19, $25,27]$, such as cycling events and cycling tourism experiences, within the pool of sports consumption.

The research also provides important managerial implications, both for businesses that belong to the cycling-related manufacturing chain (manufacturers of sports bicycles, acces- 
sories, food and supplements, etc.) and for tourist destinations that organize cycling events or promote themselves as cycling tourist resorts.

With respect to the first point (implications for sports equipment suppliers), the results of the study provide several indicators. The market is made up, first of all, of a basic segment, the "parsimonious" (37\%), with characteristics that are very different from those of the other four segments which, instead, can be considered, for different reasons, to be of a higher level. This first segment is made up of individuals who are not very involved in sporting activity, probably because they are "novices" or because they see cycling as an activity to keep fit or supplementary to other sports activities. Sportsmen and women in this segment mainly exercise where they live, consume the minimum necessary, are price-sensitive, make do with basic products and probably tend to shop in general sports shops. For these reasons, these amateur cyclists cannot be considered big spenders. However, businesses could reach them by introducing basic product lines for this specific segment, which does not have any particular technical requirements.

The other four segments, on the other hand, are those which, due to different characteristics, can be defined as "passionate cyclists" and represent the ideal target group for manufacturing companies and specialist cycle shops.

The second segment, competitive cyclists, is probably the one with greatest interest for sports bicycle manufacturers as it is significant in terms of volume (34\%) and quality of expenditure (they purchase goods and services to improve and/or maintain their sporting performance which they measure during events or in challenges with friends from outings or club mates). This segment tends to upgrade periodically, replacing old equipment with new bicycles and/or components. Finally, cyclists in this segment tend to spend proportionally less on consumables and services than on their activity because they are likely to be directly involved in the routine and special maintenance of their bikes and in preparing for races.

The third segment is made up of people who tend to flaunt their passion and are by far the "best potential customers" for both bike businesses and related service providers. This is a high-spending segment that is looking for the best available on the market because of their competitive dimension and their tendency to show off. Having substantial financial means, these sportsmen and women tend to accumulate rather than replace bicycles and other equipment.

The fourth segment is made up of enthusiasts who, even though older in terms of age, tend to practice cycling on an ongoing basis, with lower levels of performance and competitiveness but with equal or greater sociability that finds its ideal context in the cycling club. They are real entertainers of the club to which they probably devote much of their free time. This cyclist tends to replace competitive events with non-competitive events and above all with medium to long-term tourist experiences.

The fifth segment is also made up of enthusiasts with good capacity and willingness to spend who see cycling as an opportunity and a way to travel. This cluster has a much higher level of spending on cycling events and experiences than all the others and, as such, is the ideal target for service companies such as event organizers and tour operators specializing in cycling tourism.

With regards to the second point (implications for cycling destinations), it is clear that the target market segments of the organizers of cycling events and of cycling experiences are different. Despite having a small experiential segment $(7 \%)$ in common, the events should appeal in particular to the compet- itive and the ostentatious, while the cycling destinations should appeal in particular to the sociable. Ultimately, based on the evidence of this study, destination managers should be aware that in order to break into the cycling market, a differentiated marketing strategy should be adopted and an articulated product portfolio developed, in which cycling events and routes should be designed for specific targets.

\section{Conclusion}

The work carried out introduces an evident original aspect within the current sport management studies and this peculiarity derives from several aspects.

Firstly, the research conducted constitutes a new piece of knowledge which adds to the current scientific debate on the spending behavior of sportspeople. Contextualized to the world of amateur cycling, this study defines a number of stereotypes of sportsmen and women as consumers, identifying their specific characteristics in terms of sporting activity and propensity to spend. With this result, the current work represents an ideal continuation of the research that has identified and discussed the determinants of sports expenditure, and provides well defined behavioral categories.

Secondly, this article introduces an original taxonomy of expenditures related not only to sporting activity in the strict sense of the term (investment and consumption expenditures) but also to participation in events and tourism experiences. In this way, it not only ensures greater realism in the representation of expenditure behavior but also represents a link between surveys on sport and cycle tourism, i.e. between strands of study that have, until now, been considered separate and distinct.

Finally, although the work carried out has some limitations, such as the small number of observations made, it has two significant values: on the one hand, it can constitute a valid support for businesses supplying (manufacturing and distribution) sports equipment and for organizations called upon to organize and manage cycling events and routes, in their strategic activities of market segmentation; on the other hand, the approach adopted can be replicated for other sports disciplines or for other experiences and in other cultural and recreational contexts.

\section{Acknowledgement}

The authors thank cycling clubs and bicycle retailers for their collaboration in data collection and all cyclists for devoting their time to fill the questionnaire and providing information that made this research possible.

\section{References}

1. Thibaut E., Vos S., Lagae W., Puyenbroeck T. V., Scheerder J. (2016). Partaking in cycling, at what cost? Determinants of cycling expenses. International Journal of Sport Management and Marketing 16(3-6), 221-238. DOI: 10.1504/IJSMM.2016.077932.

2. Scheerder J., Vos S., Taks M. (2011). Expenditures on sport apparel. Creating consumer profiles through interval regression modelling. European Sport Management Quarterly, 11(3), 251-274.

3. ISTAT Istituto Nazionale di Statistica (2017). Sport practice in Italy. Retrieved 8 September, 2021, from https://www. istat.it/it/files/2017/10/Pratica-sportiva2015.pdf. [in Italian] 
4. ANCMA Associazione Nazionale Ciclo Motociclo Accessori (2021). Bike market. Retrieved 8 September, 2021, from https://www.ancma.news/bici-2020-da-record-oltre-2-milioni-di-pezzi-venduti/. [in Italian]

5. ISNART Istituto Nazionale di Ricerche Turistiche (2019). Cycling tourism and cycling tourists in Italy. Retrieved 8 September, 2021, from https://isnart.it/pdf/190326_Cicloturismo_Isnart.pdf. [in Italian]

6. Downward P., Rasciute S., Muniz C. (2020). Exploring the contribution of activity sports tourism to same-day visit expenditure and duration. Journal of Sport $\mathcal{E}$ Tourism 24(2), 111-126. DOI: 10.1080/14775085.2020.1784255.

7. Buning R.J., Cole Z., Lamont M. (2019). A case study of the US mountain bike tourism market. Journal of Vacation Marketing 25(4), 515-527. DOI: 10.1177/1356766719842321.

8. Chen C.A., Lee H.L. (2017). How to promote bike tourism globally. Tourism and Hospitality Management 23(1), 1-16. DOI: $10.20867 /$ thm.23.1.2.

9. Han H., Meng B., Kim W. (2017). Bike-traveling as a growing phenomenon: Role of attributes, value, satisfaction, desire, and gender in developing loyalty. Tourism Management 59, 91-103. DOI: 10.1016/j.tourman.2016.07.013.

10. Downward P., Rasciute S. (2011). Does sport make you happy? An analysis of the well-being derived from sports participation. International Review of Applied Economics 25(3), 331-348. DOI: 10.1080/02692171.2010.511168.

11. Downward P. (2007). Exploring the economic choice to participate in sports. Results from the 2002 general household survey. The International Review of Applied Economics 21(5), 633-653. DOI: 10.1080/02692170701474710.

12. Becker G.S. (1965). A theory of the allocation of time. The Economic Journal 75(299), 493-517. DOI: 10.2307/2228949.

13. Wicker P., Breuer C., Pawlowski T. (2010). Are sports club members big spenders? Findings from sport specific analyses in Germany. Sport Management Review 13(3), 214-224.

14. Lera-López F., Rapún-Gárate M. (2011). Determinants of sports participation and attendance: Differences and similarities. International Journal of Sports Marketing E Sponsorship 12(2), 167-190. DOI: 10.1108/IJSMS-12-02-2011-B007.

15. Ohl F., Taks M. (2007). Secondary socialisation and the consumption of sporting goods. Cross cultural dimensions. International Journal of Sport Management and Marketing 2(1/2), 160-174. DOI: 10.1504/IJSMM.2007.011406.

16. Thibaut E., Eakins J., Vos S., Scheerder J. (2017). Time and money expenditure in sports participation: The role of income in consuming the most practiced sports activities in Flanders. Sport Management Review 20(5), 455-467. DOI : 10.1016/j.smr.2016.12.002.

17. Hallmann K., Wicker P. (2015). Determinants of sport-related expenditure of golf players and differences between light and heavy spenders. Sport, Business and Management: An International Journal 5(2), 121-138. DOI: 10.1108/SBM09-2012-0038.

18. Wicker P., Prinz J., Weimar D. (2013). Big spenders in a booming sport: consumption capital as a key driver of triathletes' sport-related expenditure. Managing Leisure 18(4), 286-299. DOI: 10.1080/13606719.2013.809190.

19. Perić M., Dragičević D., Škorić S. (2019). Determinants of active sport event tourists' expenditure - the case of mountain bikers and trail runners. Journal of Sport $\mathcal{E}$ Tourism 19(1), 19-39. DOI: 10.1080/14775085.2019.1623064.

20. Shipway R., King K., Lee I.S., Brown G. (2016). Understanding cycle tourism experiences at the Tour Down
Under. Journal of Sport E Tourism 20(1), 21-39. DOI: 10.1080/14775085.2016.1155473.

21. Yeh C.C., Lin C.J.Y., Hsiao J.P.H., Huang C.H. (2019). The effect of improving cycleway environment on the recreational benefits of bicycle tourism. International Journal of Environmental Research and Public Health 16(18), 34-60. DOI: 10.3390/ijerphl6183460.

22. Rejón-Guardia F., García-Sastre M.A., Alemany-Hormaeche M. (2018). Motivation-based behaviour and latent class segmentation of cycling tourists: A study of the Balearic Islands. Tourism Economics 24(2), 204-217. DOI: $10.1177 / 1354816617749349$.

23. Mrnjavac E., Kovačić N., Topolšek D. (2014). The logistic product of bicycle destinations. Tourism and Hospitality Management 20(2), 171-184. DOI: 10.20867/thm.20.2.2.

24. Lamont M., Buultjens J. (2011). Putting the brakes on: Impediments to the development of independent cycle tourism in Australia. Current Issues in Tourism 14(1), 57-78. DOI: 10 .3727/154427214X13990420684365.

25. Perić M., Wise N., Dragičević D. (2017). Suggesting a service research agenda in sports tourism: working experience(s) into business models. Sport, Business and Management: An International Journal 7(1), 58-76. DOI: 10.1108/SBM-092015-0031.

26. Bąk I., Szczecińska B. (2020). Household spending on recreation and culture - a comparative analysis of selected age groups. Polish Journal of Sport and Tourism 27(2), 14-19. DOI: 10.2478/pjst-2020-0009.

27. Pencarelli T., Forlani F. (2018). Marketing in an experiential perspective: From "Goods and Service Logic" to "Experience Logic”. In T. Pencarelli, F. Forlani (eds), The Experience Logic as a New Perspective for Marketing Management (pp. 43-67). Cham: Springer.

Submitted: September 27, 2021

Accepted: November 9, 2021 